\title{
Influence of regular exercise on gastric emptying in healthy men: a pilot study
}

\author{
Juntaro Matsuzaki, ${ }^{1,2}$ Hidekazu Suzuki, ${ }^{3, *}$ Tatsuhiro Masaoka, ${ }^{1}$ Kentaro Tanaka, ${ }^{1}$ Hideki Mori ${ }^{1}$ \\ and Takanori Kanai ${ }^{1}$ \\ ${ }^{1}$ Division of Gastroenterology and Hepatology, Department of Internal Medicine and ${ }^{3}$ Medical Education Center, Keio University School of Medicine, \\ 35 Shinanomachi, Shinjuku-ku, Tokyo 160-8582, Japan \\ ${ }^{2}$ Division of Molecular and Cellular Medicine, National Cancer Center Research Institute, 5-1-1 Tsukiji, Chuo-ku, Tokyo 104-0045, Japan
}

(Received 4 March, 2016; Accepted 14 March, 2016; Published online 16 July, 2016)

Functional gastrointestinal disorders (FGIDs), including functional dyspepsia (FD), are common chronic disorders even in the younger population. Physical activity is advocated for patients with FGIDs, although the evidence is insufficient. We investigated the association between the intensity of regular exercise and gastric emptying to determine the effect of physical activity on dyspeptic symptoms. Thirty healthy individuals were selected and divided into three groups (low, moderate, and high) using the index of total exercise intensity in a week. Gastric emptying was evaluated by the ${ }^{13} \mathrm{C}$ acetate breath test. Gastroesophageal reflux symptoms, dyspeptic symptoms, stool forms, scores of anxiety and depression, and scores of sleep quality were also compared. Baseline scores of gastroesophageal reflux symptoms, anxiety, depression, and sleep quality were not different among the three groups. Gastric emptying was significantly faster in low-intensity exercise group than the moderate-intensity exercise group. Although the presence of loose stool and alcohol consumption were also associated with the intensity of regular exercise, these variables were not confounders. In conclusion, the intensity of regular exercise was independently associated with gastric emptying in healthy individuals. These baseline data would be useful for consideration of an optimal exercise intervention for the treatment of FD.

Key Words: exercise, gastric emptying, functional dyspepsia, irritable bowel syndrome, ${ }^{13} \mathrm{C}$-acetate breath test

$\mathrm{F}$ unctional gastrointestinal disorders (FGIDs), especially functional dyspepsia (FD) and irritable bowel syndrome (IBS), are common chronic disorders that impaired health-related quality of life. Physical activity is advocated for patients with IBS, although the evidence is insufficient. Physical activities have been reported to improve gas transit and abdominal distension in healthy subjects ${ }^{(1)}$ and in patients with chronic constipation. ${ }^{(2)} \mathrm{A}$ small randomized controlled trial showed that increased physical activity significantly improves the symptoms of IBS. ${ }^{(3)}$ On the other hand, the influences of physical activities on dyspeptic symptoms have not been elucidated.

Although the pathogenesis of FD is not completely understood, gastric dysmotilities, including abnormal (accelerated or delayed) gastric emptying and impaired gastric accommodation, should play some roles. Delayed gastric emptying is reported to be associated with nausea/emesis and postprandial fullness. ${ }^{(4)}$ Accelerated gastric emptying also causes gastroparetic symptoms. ${ }^{(5,6)}$ To estimate the effects of physical activity on dyspeptic symptoms, it would be worth assessing the association between gastric motility and regular physical activity. A meta-analysis of previous reports suggests that exercise intensity influences gastric emptying during and after acute exercise. ${ }^{(7)}$ However, the influence of regular exercise habit on gastric emptying has not been evaluated. Therefore, we investigated the association between the intensity of regular exercise and gastric emptying in healthy individuals.

\section{Materials and Methods}

Participants. The protocol for this study was approved by the ethics committee of the Keio University School of Medicine (No. 20120251). Thirty healthy medical students were recruited at Keio University School of Medicine. They were classified into three groups, such as the low-intensity exercise group, moderateintensity exercise group, and high-intensity exercise group, with each group containing 10 participants. Written consent was obtained from all participants. Liquid gastric emptying was measured using the ${ }^{13} \mathrm{C}$-acetate breath test. ${ }^{(8)}$ The intensity of exercise during the week before the test was assessed. In addition, questionnaires on age, height, weight, smoking and alcohol drinking habits, the Rome III criteria of $\mathrm{FD}^{(9)}$ and IBS, ${ }^{(10)}$ and the frequency of passing hard stool or loose stool were provided. Using the Bristol stool form scale, ${ }^{(10)}$ the presence of hard stool was defined as hard or lumpy stools at least $25 \%$ of the time, while the presence of loose stool was defined as loose or watery stools at least $25 \%$ of the time. We also asked to answer the following well-validated self-report questionnaires: the Pittsburgh Sleep Quality Index (PSQI), ${ }^{(11)}$ the Gastroesophageal Reflux Disease Questionnaire (GerdQ), ${ }^{(12,13)}$ and the Hospital Anxiety and Depression Scale (HADS). ${ }^{(14)}$

${ }^{13} \mathrm{C}$-acetate breath test. Participants were asked to fast for $8 \mathrm{~h}$ before testing. A test diet consisting of ${ }^{13} \mathrm{C}$-acetate $(100 \mathrm{mg})$ mixed into a liquid diet $\left(\mathrm{Racol}^{\circledR}\right.$, Otsuka, Japan), providing $200 \mathrm{kcal} / 200 \mathrm{ml}$, was administered to the participants. They exhaled air into a breath sampling bag at 11 points: prior to diet $(0 \mathrm{~min})$ and after $5,10,15,20,30,40,50,60,75$, and $90 \mathrm{~min}$. The ${ }^{13} \mathrm{CO}_{2}$ value (\%) in the breath was measured with an infrared spectrophotometer (POCone ${ }^{\circledR}$, Ostuka, Japan). The peak time of ${ }^{13} \mathrm{CO}_{2}$ excretion $\left(\mathrm{T}_{\max }\right)$ was measured. Gastric half-emptying time $\left(\mathrm{T}_{1 / 2}\right)$ was estimated using exponential power model for curve fitting.

Evaluation of the intensity of regular exercise. Exercise energy expenditure was estimated using standard metabolic equivalent values (METs). ${ }^{(15)}$ Normal walking is equivalent to 3 METs. The index of total exercise intensity (Ex) was expressed by the following formula.

Amount of exercise $(\mathrm{Ex})=$ Intensity of physical activities $(\mathrm{METs}) \times$ Duration of exercise $(\mathrm{h})$

*To whom correspondence should be addressed. E-mail: hsuzuki.a6@keio.jp 
Statistical analysis. The participants were divided into three groups based on the intensity of regular exercise. The differences of the characteristics among the three groups were compared using Pearson's chi-square test for categorical variables and KruskalWallis test for continuous variables. The differences of the $T_{\max }$ and $T_{1 / 2}$ values between two groups were compared using MannWhitney $U$ test. Statistical analyses were performed using IBM SPSS Statistics 22 (IBM Corporation, Armonk, NY). The data are expressed as means $\pm \mathrm{SD}$. Two-sided $p$ values $<0.05$ were considered statistically significant.

\section{Results}

Thirty participants were divided equally into three groups, such as the low-intensity exercise group $(<21 \mathrm{Ex} /$ week $)$, moderateintensity exercise group (21-60 Ex/week), and high-intensity exercise group ( $>60 \mathrm{Ex} /$ week). According to the Japanese Official Physical Activity Guidelines for Health Promotion in 2013 published by the Ministry of Health, Labour and Helfare in Japan, at least $23 \mathrm{Ex} /$ week of regular exercise was recommended for health promotion. Characteristics of participants in the three groups were shown in Table 1. The frequency of alcohol drinking was significantly higher in the high-intensity exercise group than in the other groups. One participant who met the Rome III criteria of FD was included in the high-intensity exercise group. One participant who met the Rome III criteria of diarrhea-type IBS was included in the low-intensity exercise group. Loose stool was more frequently observed in the low-intensity exercise group. Nobody met the criteria of the other types of IBS. The average scores of GerdQ, HADS, and PSQI were not different among the three groups.

The average $T_{\max }$ levels were significantly higher in the moderateintensity exercise group than in the low-intensity exercise group (Fig. 1). The average $T_{1 / 2}$ levels were also the highest in the moderate-intensity group. These results showed that gastric emptying was delayed in the moderate-intensity exercise group as compared with that in the low- or high-intensity group. Regarding the difference of alcohol consumption among the three groups, the association between $T_{\max }$ or $\mathrm{T}_{1 / 2}$ and alcohol consumption was analyzed (Table 2). We confirmed that the difference of alcohol consumption did not affect $T_{\max }$ or $\mathrm{T}_{1 / 2}$. In addition, $\mathrm{T}_{\max }$ or $\mathrm{T}_{1 / 2}$ was not associated with the presence of loose stool (Table 3 ). These data showed that gastric emptying was independently associated with the intensity of regular exercise in healthy individuals.

\section{Discussion}

The previous reports suggest that gastric emptying appears to be accelerated during low-intensity exercise, and delayed during high-intensity exercise. ${ }^{(7)}$ The present study showed that the intensity of regular exercise also affects gastric emptying in resting conditions. Since there were no differences of age, gender, mental health conditions, and sleep quality among the three exercise-intensity groups, the intensity of regular exercise would be independently associated with gastric emptying.

According to our results, gastric emptying was faster in the low-intensity exercise group than in the moderate-intensity exercise group. This suggests that dyspeptic symptoms, which would be caused by accelerated gastric emptying, might be improved by the intervention of moderate-intensity regular exercise. In the lowintensity group, loose stool was more frequently observed than in the other groups. It is well-known that accelerated gastric emptying often causes diarrhea. ${ }^{(16)}$ Lawal et $a l^{(17)}$ reported that $70 \%$ of patients with accelerated gastric emptying had diarrhea. Therefore, a possible reason for the decreased frequency of loose stool in moderate-intensity exercise groups would be the improvement of accelerated gastric emptying.

According to the data of $\mathrm{T}_{1 / 2}$, gastric emptying was also faster

Table 1. Differences of characteristics depending on the intensity of exercise

\begin{tabular}{|c|c|c|c|c|}
\hline & $\begin{array}{c}\text { Low } \\
(<21 \text { Ex/week }) \\
(n=10)\end{array}$ & $\begin{array}{c}\text { Moderate } \\
(21-60 \text { Ex/week) } \\
(n=10)\end{array}$ & $\begin{array}{c}\text { High } \\
(>60 \text { Ex/week }) \\
(n=10)\end{array}$ & $p$ value \\
\hline Age $(y)($ Mean \pm SD) & $20.9 \pm 0.9$ & $20.3 \pm 2.2$ & $20.3 \pm 1.2$ & $0.30^{\dagger}$ \\
\hline Current smoker & $0(0 \%)$ & $0(0 \%)$ & $0(0 \%)$ & $0.35^{\ddagger}$ \\
\hline Alcohol consumption & & & & $0.002^{\ddagger}$ \\
\hline none & $2(20 \%)$ & $5(50 \%)$ & $3(30 \%)$ & \\
\hline less than 4 times a month & $8(80 \%)$ & $0(0 \%)$ & $2(20 \%)$ & \\
\hline $1-2$ days a week & $0(0 \%)$ & $3(30 \%)$ & $5(50 \%)$ & \\
\hline 3-4 days a week & $0(0 \%)$ & $2(20 \%)$ & $0(0 \%)$ & \\
\hline 5-7 days a week & $0(0 \%)$ & $0(0 \%)$ & $0(0 \%)$ & \\
\hline BMI $\left(\mathrm{kg} / \mathrm{m}^{2}\right)($ Mean $\pm \mathrm{SD})$ & $20.6 \pm 1.1$ & $22.2 \pm 2.1$ & $22.0 \pm 3.5$ & $0.14^{\dagger}$ \\
\hline GerdQ (Mean \pm SD) & $6.3 \pm 0.7$ & $6.2 \pm 0.6$ & $6.1 \pm 0.6$ & $0.84^{\dagger}$ \\
\hline Functional dyspepsia & $0(0 \%)$ & $0(0 \%)$ & $1(10 \%)$ & $0.36^{\ddagger}$ \\
\hline Postprandial fullness & $0(0 \%)$ & $0(0 \%)$ & $2(20 \%)$ & $0.12^{\ddagger}$ \\
\hline Early satiation & $0(0 \%)$ & $0(0 \%)$ & $0(0 \%)$ & $\mathrm{NA}^{\ddagger}$ \\
\hline Epigastric pain & $0(0 \%)$ & $0(0 \%)$ & $0(0 \%)$ & $\mathrm{NA}^{\ddagger}$ \\
\hline Epigastric burning & $1(10 \%)$ & $0(0 \%)$ & $0(0 \%)$ & $0.36^{\ddagger}$ \\
\hline Irritable bowel syndrome & $1(10 \%)$ & $0(0 \%)$ & $0(0 \%)$ & $0.36^{\ddagger}$ \\
\hline Hard stool & $0(0 \%)$ & $1(10 \%)$ & $1(10 \%)$ & $0.59^{\ddagger}$ \\
\hline Loose stool & $4(40 \%)$ & $0(0 \%)$ & $1(10 \%)$ & $0.04^{\ddagger}$ \\
\hline HADS-A (Mean \pm SD) & $3.0 \pm 2.4$ & $5.1 \pm 3.4$ & $3.5 \pm 3.3$ & $0.28^{\dagger}$ \\
\hline HADS-D $($ Mean \pm SD $)$ & $3.5 \pm 2.8$ & $4.6 \pm 3.9$ & $4.3 \pm 3.0$ & $0.80^{\dagger}$ \\
\hline PSQI (Mean \pm SD) & $4.5 \pm 2.4$ & $4.0 \pm 2.1$ & $4.7 \pm 1.8$ & $0.81^{\dagger}$ \\
\hline
\end{tabular}

Bold values indicate significant differences $(p<0.05)$; BMI, body mass index; GerdQ, gastroesophageal reflux disease questionnaire; HADS-A, hospital anxiety and depression scale-anxiety; HADS-D, hospital anxiety and depression scale-depression; PSQI, the Pittsburgh sleep quality index; NA, not analyzed; ${ }^{+}$Kruskal-Wallis test; ${ }^{\ddagger}$ Pearson's $\chi^{2}$ test. 

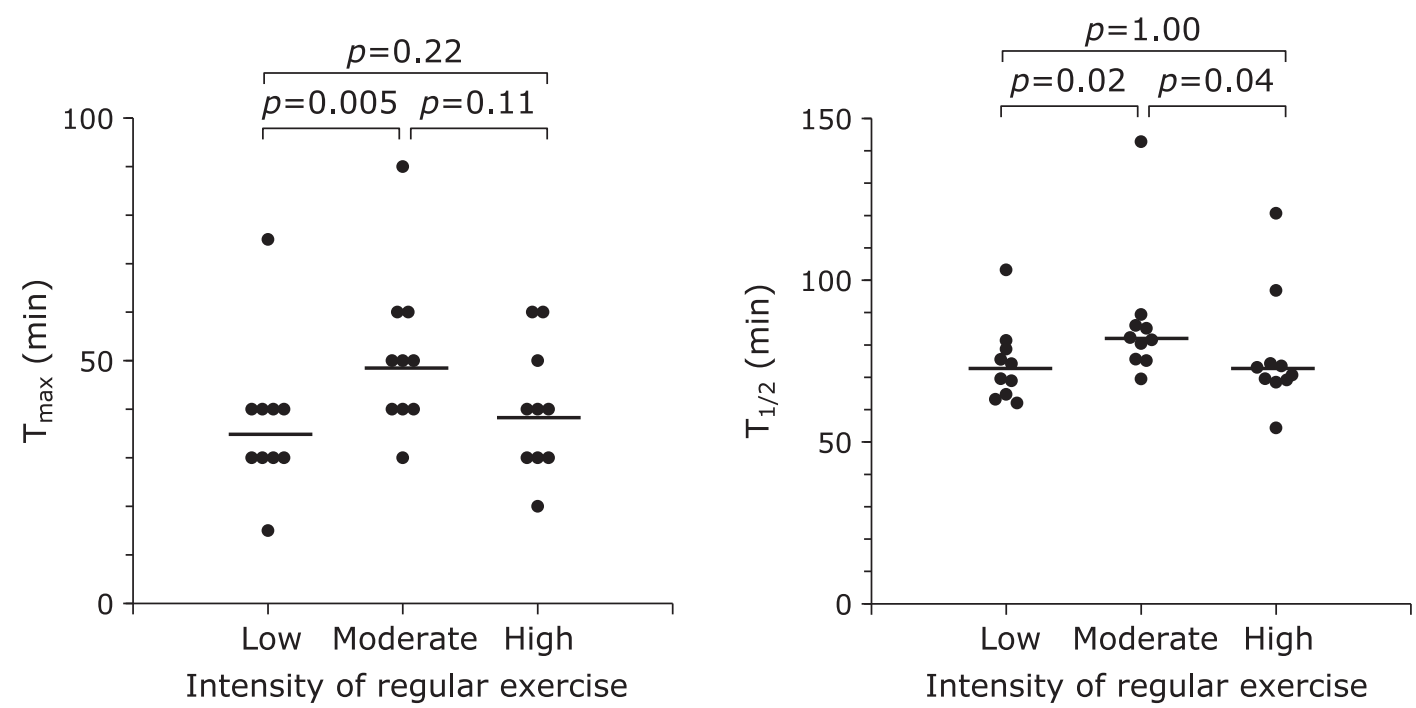

Fig. 1. Dot plots are shown to compare the gastric emptying among individuals with low, moderate, and high intensity of regular exercise $(n=10$ in each group). Gastric emptying was evaluated by the ${ }^{13} \mathrm{C}$-acetate breath test. The average levels of $\mathrm{T}_{\max }$ (left panel) and $\mathrm{T}_{1 / 2}$ (right panel) between two groups were compared using Mann-Whitney $U$ test.

Table 2. Association between alcohol consumption and gastric emptying

\begin{tabular}{|c|c|c|c|c|}
\hline Frequency of alcohol consumption & $\mathrm{T}_{\max }(\min )$ & $p$ value $^{\dagger}$ & $\mathrm{T}_{1 / 2}(\min )$ & $p$ value $^{\dagger}$ \\
\hline None $(n=10)$ & $47.0 \pm 18.9$ & 0.17 & $88.0 \pm 24.9$ & 0.44 \\
\hline$<4$ days/month $(n=10)$ & $36.0 \pm 16.3$ & & $73.6 \pm 13.3$ & \\
\hline $1-2$ days/week $(n=8)$ & $42.5 \pm 10.4$ & & $76.0 \pm 10.1$ & \\
\hline 3-4 days/week $(n=2)$ & $55.0 \pm 7.1$ & & $77.8 \pm 3.8$ & \\
\hline
\end{tabular}

${ }^{\dagger}$ Kruskal-Wallis test.

Table 3. Association between the frequency of loose stool and gastric emptying

\begin{tabular}{lcccc}
\hline Loose stool & $\mathrm{T}_{\max }(\mathrm{min})$ & $p$ value $^{\dagger}$ & $\mathrm{T}_{1 / 2}(\min )$ & $p$ value $^{\dagger}$ \\
\hline Absent & $44.4 \pm 16.8$ & 0.14 & $81.1 \pm 18.7$ & 0.14 \\
Present & $34.0 \pm 5.4$ & & $70.3 \pm 6.7$ & \\
\hline
\end{tabular}

${ }^{\dagger}$ Mann-Whitney $U$ test.

in the high-intensity exercise group than in the moderate-intensity exercise group. In endurance athletes, gastrointestinal symptoms such as nausea, vomiting, bloating, urge to defecate, and diarrhea, are well documented. ${ }^{(18,19)}$ During high-intensity exercise, gastric emptying is thought to be delayed mainly through the overactivation of the sympathetic nervous system. On the other hand, exercise training may reduce resting blood pressure and decrease the activity of sympathetic nerves, ${ }^{(20)}$ suggesting that highintensity exercise may accelerate gastric emptying. Large fluctuations in gastric emptying during rest and high-intensity exercise might be a possible cause of dyspeptic symptoms in athletes.

A clear limitation of this pilot study is its small sample size. Multivariable analysis was unavailable due to the small sample size. Participants are all healthy young men, which limits generalizability. The other limitation is that we did not evaluate solid gastric emptying. Although both liquid and solid gastric emptying were shown to be associated with dyspeptic symptoms, ${ }^{(21)}$ underlining mechanisms of impaired gastric emptying of solid and liquid meal would be different each other. Thus, further validation of our results is required in the general population as well as the population with dyspeptic symptoms.
In conclusion, the intensity of regular exercise was independently associated with gastric emptying. Gastric emptying was faster in the low- and high-intensity exercise groups than in the moderate-intensity exercise group. This suggests that accelerated gastric emptying might cause dyspeptic symptoms in individuals performing regular low or high-intensity exercise. The moderateintensity exercise intervention might improve the dyspeptic symptoms caused by accelerated gastric emptying. Thus, the regular exercise intensity should be taken into account when considering the underlying mechanisms of dyspeptic symptoms. Further investigations are required to understand the association between regular exercise and gastric dysmotility.

\section{Acknowledgments}

This study was supported by a Grant-in-Aid for Young Scientists (B) (26860527, to JM), a Grant-in-Aid for Scientific Research (B) (25293178, to HS), and a Grant-in-Aid for Challenging Exploratory Research (26670065, to HS) from the Japan Society for the Promotion of Science (JSPS), MEXTSupported Program for the Strategic Research Foundation at 
Private Universities (S1411003, to HS), the Princess Takamatsu Cancer Research grants (to HS), a grant from Takeda Science Foundation (to JM), the Medical School Faculty and Alumni Grant from Keio University Medical Science Fund (to JM), and Keio Gijuku Academic Development Funds (to JM and to HS).

\section{Conflict of Interest}

During the last 2 years, Author HS received scholarship funds for the research from Astellas Pharm Inc., Astra-Zeneca K.K., Otsuka Pharmaceutical Co., Ltd., Takeda Pharmaceutical Co., Ltd. and Zeria Pharmaceutical Co., Ltd., and received service honoraria from Astellas Pharm Inc., Astra-Zeneca K.K., Otsuka

\section{References}

1 Dainese R, Serra J, Azpiroz F, Malagelada JR. Effects of physical activity on intestinal gas transit and evacuation in healthy subjects. Am J Med 2004; 116: 536-539.

2 De Schryver AM, Keulemans YC, Peters HP, et al. Effects of regular physical activity on defecation pattern in middle-aged patients complaining of chronic constipation. Scand J Gastroenterol 2005; 40: 422-429.

3 Johannesson E, Simrén M, Strid H, Bajor A, Sadik R. Physical activity improves symptoms in irritable bowel syndrome: a randomized controlled trial. Am J Gastroenterol 2011; 106: 915-922.

4 DiBaise JK, Patel N, Noelting J, Dueck AC, Roarke M, Crowell MD. The relationship among gastroparetic symptoms, quality of life, and gastric emptying in patients referred for gastric emptying testing. Neurogastroenterol Motil 2016; 28: 234-242.

5 Singh A, Gull H, Singh RJ. Clinical significance of rapid (accelerated) gastric emptying. Clin Nucl Med 2003; 28: 658-662.

6 Kusano M, Zai H, Shimoyama Y, et al. Rapid gastric emptying, rather than delayed gastric emptying, might provoke functional dyspepsia. $J$ Gastroenterol Hepatol 2011; 26 (Suppl 3): 75-78.

7 Horner KM, Schubert MM, Desbrow B, Byrne NM, King NA. Acute exercise and gastric emptying: a meta-analysis and implications for appetite control. Sports Med 2015; 45: 659-678.

8 Bjorkman DJ, Moore JG, Klein PD, Graham DY. 13C-bicarbonate breath test as a measure of gastric emptying. Am J Gastroenterol 1991; 86: 821-823.

9 Tack J, Talley NJ, Camilleri M, et al. Functional gastroduodenal disorders. Gastroenterology 2006; 130: 1466-1479.

10 Longstreth GF, Thompson WG, Chey WD, Houghton LA, Mearin F, Spiller RC. Functional bowel disorders. Gastroenterology 2006; 130: 1480-1491.

11 Buysse DJ, Reynolds CF 3rd, Monk TH, Berman SR, Kupfer DJ. The Pittsburgh Sleep Quality Index: a new instrument for psychiatric practice and research. Psychiatry Res 1989; 28: 193-213.
Pharmaceutical Co., Ltd., Takeda Pharmaceutical Co., Ltd. and Zeria Pharmaceutical Co., Ltd. Author TK received scholarship funds for the research from Astellas Pharm Inc., Astra-Zeneca K.K., Otsuka Pharmaceutical Co., Ltd., Takeda Pharmaceutical Co., Ltd., Eisai Pharmaceutical Co., Ltd., Zeria Pharmaceutical Co., Ltd., Tanabe Mitsubishi Pharmaceutical Co., Ltd. JIMRO Co., Ltd. and Kyorin Pharmaceutical Co., Ltd., and received service honoraria from Astellas Pharm Inc., Eisai Pharmaceutical Co., Ltd., JIMRO Co., Ltd., Tanabe Mitsubishi Pharmaceutical Co., Ltd., Otsuka Pharmaceutical Co., Ltd., Takeda Pharmaceutical Co., Ltd., Miyarisan Pharmaceutical Co., Ltd. and Zeria Pharmaceutical Co., Ltd.

12 Jones R, Junghard O, Dent J, et al. Development of the GerdQ, a tool for the diagnosis and management of gastro-oesophageal reflux disease in primary care. Aliment Pharmacol Ther 2009; 30: 1030-1038.

13 Suzuki H, Matsuzaki J, Okada S, Hirata K, Fukuhara S, Hibit T. Validation of the GerdQ questionnaire for the management of gastro-oesophageal reflux disease in Japan. United European Gastroenterol J 2013; 1: 175-183.

14 Zigmond AS, Snaith RP. The hospital anxiety and depression scale. Acta Psychiatr Scand 1983; 67: 361-370.

15 National Institute of Health and Nutrition. Exercise and Physical Activity Reference for Health Promotion 2006 (EPAR 2006): Physical Activity Exercise, and Physical Fitness. Tokyo: Ministry of Health, Labour and Welfare of Japan, 2006.

16 Charles F, Phillips SF, Camilleri M, Thomforde GM. Rapid gastric emptying in patients with functional diarrhea. Mayo Clin Proc 1997; 72: 323-328.

17 Lawal A, Barboi A, Krasnow A, Hellman R, Jaradeh S, Massey BT. Rapid gastric emptying is more common than gastroparesis in patients with autonomic dysfunction. Am J Gastroenterol 2007; 102: 618-623.

18 Strid H, Simrén M, Störsrud S, Stotzer PO, Sadik R. Effect of heavy exercise on gastrointestinal transit in endurance athletes. Scand J Gastroenterol 2011; 46: 673-677.

19 van Nieuwenhoven MA, Brouns F, Brummer RJ. Gastrointestinal profile of symptomatic athletes at rest and during physical exercise. Eur J Appl Physiol 2004; 91: 429-434.

20 Mueller PJ. Exercise training and sympathetic nervous system activity: evidence for physical activity dependent neural plasticity. Clin Exp Pharmacol Physiol 2007; 34: 377-384.

21 Sarnelli G, Caenepeel P, Geypens B, Janssens J, Tack J. Symptoms associated with impaired gastric emptying of solids and liquids in functional dyspepsia. Am J Gastroenterol 2003; 98: 783-788. 